\title{
Understanding scientists is key for science
}

\author{
Stuart Higgins reflects on his experience as both a scientist and a producer of the podcast Scientists not the Science.
}

'd grown obsessed with podcasts. I liked in particular The Comedian's Comedian with Stuart Goldsmith, where the host interviews comedians about their craft - I loved listening, empathizing with the guests' angst around pursuing a relatively unstable career path. So, once the stress of finishing my PhD subsided in 2014, I started wondering - could I interview scientists and get them to help me understand this science career I didn't know much about? In February 2015, I published the first episode of my podcast, Scientists not the Science (https://www.scinotsci.com). What began as an opportunity for me to collect career tips from other scientists has gradually evolved into an exploration of their experiences.

I've found that everybody has a unique journey, albeit with commonly recurring themes. This diversity of experience means that one person's 'wisdom' of how to be a scientist is often a product of their circumstances. That doesn't necessarily make their advice bad, but it certainly won't apply to everyone in every situation. So, with that caveat and after four years of interviews, here are a few pieces of such advice I find myself thinking about again and again.

Choose wisely. Every experiment, collaboration and paper costs time. In one of my early interviews, chemist Chris Hunter told me how being selective in science is critical to using your time wisely. I later learnt that economists call this 'opportunity cost' (doing one thing means you're not doing another).

Learning about imposter syndrome the feeling of doubting your own success - was a revelation to me. I hadn't realized that so many other scientists felt it too. I still feel this self-doubt, but at least I can better rationalize the thoughts now. I also learnt that working abroad, in a non-native language, or being part of an underrepresented group in science can exacerbate those feelings.

Lead by example. When trying to inspire children, teacher and scientist Carole Kenrick highlighted that isolated visits by scientists to schools are unlikely to have an impact. This observation is backed up by the extensive ASPIRES research project (https://go.nature.com/2Rlat9o), which

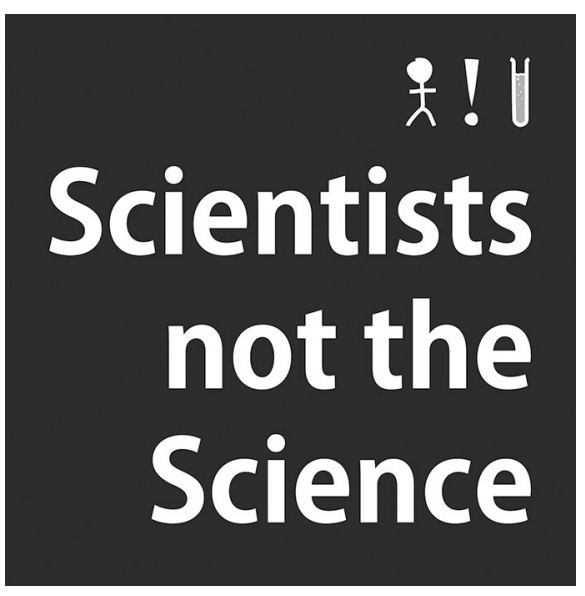

Logo of the podcast Scientists not the Science. Credit: https://www.scinotsci.com/

studies young people's aspiration to become scientists. What does attract scientists of every age is showing them realistic and attainable role models. Geologist Chris Jackson told me how he tries to be open about his interests and life outside of academia, so that his students are not only inspired by the science, but also by the broader benefits of the career.

It's not just about papers. Each of the many successful, talented scientists I have interviewed is a robust rebuke to the 'Carl Sagan effect', the incorrect assumption that a scientist doing public engagement is worse than a scientist who focuses wholly on their research. Ironically, the opposite is true: scientists with higher levels of engagement tend to publish more (S. Martinez-Conde, J. Neurosci. 36, 2077-2082; 2016).

There aren't enough jobs in academic science for every researcher. If every academic at the University of Cambridge (or indeed my current institute) retired tomorrow, there would still be twice as many postdocs as jobs available. This wouldn't be a problem if I had known this from the start (and not when I was well into my first postdoc). The issue is made worse by science's failure to recognize success outside of academia. This can leave those who've pursued successful careers in other sectors feeling as though they have 'failed' as a scientist, which in itself fails to recognize the many social and economic benefits of a scientifically literate workforce.

I now believe that understanding and discussing ideas like these is essential, both on a human level and for the health of the scientific enterprise itself. I've seen great scientists leave academia - not because they want to, but because the system has crushed them. This has a huge impact on scientific research, as science and scientists are not separable. If history is written by the victors, science is written by the scientists who publish papers, and if you've left the academic career path because you couldn't see any role models who looked like you, because of crippling imposter syndrome, or because those few academic jobs only went to a group you don't belong to, the stories of science aren't told by you. And when science is told by scientists that do not consider how their own stories may not reflect the whole of society, this can result in dangerously unreliable results - read Angela Saini's books Inferior and Superior to be horrified by the sexist, racist science that many assume is fact.

I often find this feels overwhelming. It feels that there are so many things I should be better at, and all while making sure I look after my own health so I can be the scientist I think I should be. My approach so far has been to try and apply what I've learnt to my different roles, such as helping students focus on the most important aspects of their research, raising and highlighting issues such as imposter syndrome within research groups, and by supporting those who do great things.

It's also important to note how overwhelmingly positive the experience of talking to other scientists is. I doubt I would have remained in academia this long if I hadn't been also inspired by incredible individuals who have shown me what academic science can be, not just what it often is.

\section{Stuart G. Higgins (D) \\ Imperial College London, London, UK. e-mail:stuart.higgins@imperial.ac.uk}

Published online: 19 September 2019 https://doi.org/10.1038/s41563-019-0432-2 